REVISTA ANDALUZA DE ANTROPOLOGÍA.

NÚMERO 4: ENCRUCIJADAS PARA LAS SOCIEDADES PESQUERAS DEL SUR EN EL MARCO DE LA

GLOBALIZACIÓN. MARZO DE 2013

ISSN 2174-6796

[pp. 10-32]

http://dx.doi.org/10.12795/RAA.2013.i04.02

Fecha de recepción: 10/01/2013

Fecha de aceptación: 31/01/2013

\title{
¿ÁREAS MARINAS PROTEGIDAS PARA MEJORAR LA GOBERNABILIDAD LOCAL? EL CASO DE LA RESERVA MARINA DE LA RESTINGA ${ }^{1}$
}

\author{
Raquel de la Cruz Modino \\ José J. Pascual Fernández \\ Instituto Universitario de Ciencias Políticas y Sociales. Universidad de La Laguna
}

\section{Resumen.}

La gobernabilidad (Kooiman, 2008) de los espacios marinos protegidos constituye un reto para las políticas actuales de protección de los ecosistemas. Los conflictos en torno a la creación y funcionamiento de estos modelos institucionales son mucho más frecuentes de lo deseable, llevando a cuestionar en ocasiones su viabilidad. En este trabajo analizamos el proceso de creación de la Reserva Marina Punta de La Restinga-

\footnotetext{
1. Los datos y propuestas contenidas en estas páginas se relacionan con el desarrollo de diversos proyectos del Plan Nacional de $\mathrm{I}+\mathrm{D}+\mathrm{i}$ de España, coordinados por el grupo de investigación Pescatur, el cual lleva trabajando desde el año 2001 sobre un conjunto de casos localizados en las Islas Canarias, y en las regiones de Galicia y Cataluña principalmente. Concretamente, se reflejan algunos resultados del proyecto GOBAMP: "El análisis de gobernabilidad aplicado al proceso de creación de Áreas Marinas Protegidas" (Ref.: CSO2009-09802), financiado por el Ministerio de Economía y competitividad, dedicado específicamente a examinar la situación de las AMPs desde su punto cero o step zero (Chuenpagdee y Jentoft, 2007). El proyecto ha analizado, entre otras cuestiones cómo se articula y comunica la idea de protección, cómo toma forma y se construye la imagen de un AMP o el diseño institucional propuesto, contemplando detenidamente las condiciones que han podido facilitar (o entorpecer) el éxito de la propuesta de protección en un contexto sociocultural dado. El grupo de investigación Pescatur se localiza en el Instituto de Ciencias Políticas y Sociales de la Universidad de La Laguna. Desde 1979 ha desarrollado diferentes proyectos de investigación sobre poblaciones de pescadores artesanales o de bajura en España. Entre sus líneas de trabajo destaca el análisis sobre la articulación entre sociedad y protección de la naturaleza desde la perspectiva de la actividad pesquera, y los estudios sobre gobernanza en ámbitos marinos. Debemos reconocer la colaboración de la Red de Reservas Marinas de la Secretaría General del Mar, del Ministerio de Agricultura, Alimentación y Medio Ambiente en nuestras investigaciones. Queremos agradecer también el apoyo financiero de la Agencia Canaria de Investigación, Innovación y Sociedad de la Información, a través del Proyecto Estructurante de Ciencias Marinas.
} 
Mar de las Calmas, considerando especialmente la implicación de los usuarios locales en su gestación. Ponemos el énfasis en una serie de factores que entendemos esenciales para su éxito, destacando las características de un proceso que permitió que el diseño institucional y las imágenes que definían en la mente de los locales a esta figura de protección, se fueran gestando lentamente con la implicación tanto de los usuarios como de científicos y autoridades. Los procesos de creación de estas figuras con frecuencia divergen claramente de lo que hemos hallado en este caso, y asumimos que esto conduce a muchas de las dificultades para su implementación y gestión. Por ello, enfatizar los esfuerzos necesarios en las fases iniciales de la gestación de los espacios protegidos suele ser esencial para su viabilidad futura.

Palabras clave: Áreas marinas protegidas, pesca artesanal, gobernanza, gobernabilidad, punto cero, turismo, reservas marinas

\section{Abstract.}

The governability (Kooiman, 2008) of marine protected areas represents a challenge for ecosystem conservation policies. Conflicts related to the creation and management of these institutional models are much more frequent than desirable, bringing into question its viability. This paper analyzes the creation process of the Marine Reserve Punta de La Restinga-Mar de las Calmas considering the involvement of local users from its early steps. Furthermore, it emphasizes a number of factors that we consider essential to understand the success of this marine reserve, highlighting how the institutional design and the formation of images took shape in the minds of the locals, helping to accept and support this model of protection. Locals got the support from scientist and administration in this development. The creation processes of Marine Protected Areas may diverge frequently from the case of La Restinga, and this may be related with sources of conflict. For this reason, we underline that the efforts to be placed during the inception of MPAs may be essential for their viability.

Keywords: Marine protected area, small-scale fisheries, governance, governability, step zero, tourism, marine reserves.

\section{INTRODUCCIÓN}

Las Áreas Marinas Protegidas -AMPs, a partir de ahora- se han definido como "cualquier área del territorio intermareal o submareal, cuyos fondos, aguas, flora y fauna asociadas, así como sus aspectos históricos y culturales, han sido preservados por las leyes o cualquier otra medida efectiva para proteger todo o parte del medio ambiente incluido en la misma" (Kelleher y Kenchington, 1992). En España, donde se localiza el caso de estudio que presentamos en este texto, las primeras demandas oficiales de protección marina se elevaron en los años setenta y principios de los ochenta del siglo pasado en 
el litoral mediterráneo, en la costa de L’Estartit (Gerona, Cataluña) y la Bahía de Palma (Palma de Mallorca, Islas Baleares). Desde entonces se han declarado numerosas AMPs ${ }^{1}$ tanto en las costas mediterráneas como atlánticas, con diferentes categorías, marcos legislativos, objetivos, colectivos implicados y procesos de implementación. En el año 2011 se contabilizaron 28 AMPs, considerando sólo las situadas en el ámbito marítimocostero y dejando fuera las figuras acogidas a un régimen de protección procedente de la UE o a nivel internacional, pero sin una traducción estricta en el ordenamiento español, así como otros espacios protegidos donde solo pesan prohibiciones sobre artes o prácticas pesqueras, como las zonas para la pesca submarina (De la Cruz Modino y Pascual Fernández, 2011: 71).

A priori no existe un modelo de AMP estándar, ni entre el conjunto de las españolas ni a nivel internacional. Muchas se caracterizan por su diversidad y los contrastes en diferentes aspectos tales como el tamaño, los usos permitidos, las comunidades biológicas afectadas, los sistemas de planeamiento y gestión implementados, las condiciones a la explotación de los recursos que pueden ser impuestas, etc. Generalmente, casi todas (o todas) implican cerrar ciertas áreas a las actividades extractivas de manera temporal o permanentemente, e imponen regulaciones de acceso para todo tipo de usuarios, ejerzan éstos actividades profesionales (como los pescadores) o de índole recreativa.

Los principios por los que las AMPs son impulsadas suelen ser diversos, tanto como sus metas y objetivos, que pueden modificarse a lo largo del tiempo (Jentoft; Chuenpagdee et al, 2011). Un AMP puede ser diseñada atendiendo a una única o a una combinación de razones (Salm; Clark et al, 2000: 13-14). En algunas se prioriza la protección de especies amenazadas como los mamíferos marinos, como por ejemplo en el Santuario Nacional Marino de la Bahía de Monterrey y el Santuario Nacional Marítimo de la Ballena Jorobada de las Islas Hawai, creados por el gobierno de los Estados Unidos - EEUU - en 1992. Otro ejemplo lo encontramos en Alaska en 1925, cuando el Glaciar Bay National Monument fue protegido con el fin de salvaguardar principalmente la "belleza escénica" del glaciar y la bahía, pero sirviendo de facto para conservar el hábitat de las ballenas (Hoyt, 2005: 14). En países como Kenia, Filipinas y Belice por ejemplo, se han creado zonas marinas protegidas para colaborar en la gestión de los recursos pesqueros y el turismo. Las AMPs españolas podrían ser definidas en este sentido como áreas multi-específicas, ya que sirven a una variedad de objetivos sectoriales asociados a la gestión pesquera, la planificación turística, la educación, la investigación y la divulgación científica.

1. Siendo estrictos tendríamos que aclarar que, hoy por hoy en este país, sería más correcto emplear la expresión "Espacios Marinos Protegidos", para referirnos de forma genérica a la multiplicidad de figuras de protección marina que pueden ser implementadas. El AMP tan sólo es un tipo entre las existentes desde la aprobación de la Ley 42/2007, de 13 de diciembre, del Patrimonio Natural y de la Biodiversidad. No obstante, empleamos este apelativo para hablar de todas ellas de manera genérica, pues AMP es el concepto más popular en la literatura científica a nivel internacional. 
En el caso de las "reservas marinas" consideradas de interés pesquero, como la de $\mathrm{La}$ Restinga que tratamos en este texto, "el objetivo principal es la sostenibilidad de las pesquerías artesanales" (Revenga, 2003: 101). Ello marca una importante diferencia al respecto de otras figuras de protección como los Parques Nacionales Marítimo-Terrestres, las vedas o los Parques Naturales; y coloca a los pescadores profesionales de bajura o artesanales en el centro de su desarrollo. En cuanto a las administraciones titulares o responsables, debemos detallar que cuando las AMPs son declaradas afectando el "mar territorial" ${ }^{2}$ su responsabilidad es asumida con mayor frecuencia por la administración pesquera a nivel nacional - aun de manera compartida con los gobiernos regionales en ciertas ocasiones-, y no tanto por otras de índole medioambiental. Hasta el año 2007 inclusive, todas las AMPs localizadas en aguas del mar territorial, fueran de titularidad compartida o no, fueron declaradas como "reservas marinas" e implementadas como figuras "de interés pesquero" en base a la Orden Ministerial de 11 de mayo de 1982 (BOE $\mathrm{n}^{\circ} 125,26$ de mayo 1982) y a la Ley 3/2001, de 26 de marzo, de Pesca Marítima del Estado (BOE no 75, de miércoles 28 marzo de 2001) ${ }^{3}$. Cuando las AMPs se extienden enteramente dentro de las aguas interiores, las figuras o denominaciones, así como sus administraciones responsables, pueden variar grandemente entre unas comunidades autónomas y otras —véase De la Cruz Modino y Pascual Fernández (2011: 71-72). Un buen ejemplo de ellas lo representa la Comunidad Autónoma de Cataluña que cuenta

2. Las llamadas "aguas exteriores" comprenden el espacio denominado "mar territorial" (que se extiende aproximadamente hasta la plana abisal), el cual se ha ampliado desde las tres millas náuticas fijadas a inicios del siglo XVIII hasta las 12 millas estipuladas en 1982, tal y como explican Suárez de Vivero y Rodríguez Mateos (2007); mientras que las aguas interiores son aquellas aguas comprendidas entre puntas, bahías, ensenadas, puertos, canales marítimos, radas, estuarios, etc., siempre dentro de la línea de base recta. La Constitución Española contempla las aguas interiores, como un espacio en el que las Comunidades Autónomas podrán asumir competencias en materia de pesca y protección del medio ambiente.

3. La Orden Ministerial -OM- de 11 de mayo de 1982 (BOE n 125, 26 de mayo 1982), se apoyaba y bebía directamente del Real Decreto 681/1980, de 28 de marzo, de ordenación de la actividad de pesca marítima, la cual había previsto el establecimiento de vedas zonales. Esta OM definió una serie de estrategias y medidas destinadas a la repoblación en las aguas de la plataforma continental y en la zona económica exclusiva, en el mar territorial y en las aguas interiores marítimas, sin perjuicio de las competencias que sobre esta materia pudieran corresponder a las CCAA. Tal y como detallaba “(...) la Dirección General de Ordenación Pesquera, por si o a petición de parte, previo informe de la Comandancia Militar de Marina correspondiente y del Instituto Español de Oceanografía, oída la Federación Nacional de Cofradías de Pescadores, podrá establecer zonas de reserva, en las que quedará prohibida la extracción de alguna o de todas las especies de fauna y flora marinas que se determinen por el tiempo que se establezca". Además aclaraba que se podría pescar con artes e instrumentos autorizados en las zonas de protección definidas, observando las normas que en materia de pesca y extracción estuvieran en vigor. La Ley 3/2001, de 26 de marzo, de Pesca Marítima del Estado (BOE n 75, de miércoles 28 marzo de 2001) se volvió a referir a la figura de reserva marina, considerando a ésta como una herramienta específica en el logro de la explotación sostenida de los recursos de interés pesquero. 
entre sus costas con dos Parques Naturales Marítimo-Terrestres, gestionados por el gobierno autonómico (el del Cap de Creus y el que envuelve a las Islas Medas), una veda que ha disfrutado de la consideración de reserva marina (Cap Negre/Ses negres), otras dos AMPs en deltas fluviales acogidas a diferentes figuras de protección (el Espacio Natural del Delta del Llobregat y el Parque Natural del Delta del Ebro), y una Reserva Marina "de interés pesquero" gestionada por la Secretaría General del Mar —SEGEMAR — (Massía Blanca).

Cada AMP cuenta con su propia historia y resulta de un proceso de negociación, siendo su punto cero o step zero (Chuenpagdee y Jentoft, 2007), esto es, las primeras fases de planteamiento o incluso el primer bosquejo de la propia idea de protección, decisivo para entender su futuro desarrollo y aceptación entre los colectivos de interés implicados. Las AMPs no son meras soluciones técnicas ni actúan únicamente sobre entornos o elementos biofísicos del ecosistema, sino que son reguladoras y facilitadoras de la acción humana y la interacción con el ambiente (Jentoft; van Son et al, 2007), impactando sobre las vías en las que las poblaciones se relacionan con los recursos bajo protección. Se trata pues, de intervenciones sociopolíticas, de productos socioculturales resultantes de procesos de interacción y negociación en los que generalmente varias partes, grupos y/o colectivos, tienen que decidir el qué, el cómo, el dónde y el porqué o para qué de la protección. De ahí el interés de trabajar durante las fases de propuesta, diseño, implementación y postimplementación de las mismas desde el ámbito de las Ciencias Sociales.

\section{MATERIALES Y MÉTODOS}

En este texto, defendemos que los retos de la protección del medio marino y la gestión de las AMPs, como otros desafíos sociales, son el resultado de la interacción entre varios factores que rara vez son plenamente conocidos ni están causados ni se hallan bajo el control de un solo actor (Prats i Català, 2005). Se trata por ello de cuestiones abordables o que atañen a una reflexión sobre o desde las teorías de la gobernanza. El planteamiento concreto de la gobernanza interactiva (Kooiman; Bavinck et al, 2005) pone el énfasis en la calidad de las interacciones de gobierno precisamente, y nos invita a valorar las condiciones de gobernabilidad dado un contexto social y ecológico determinado (Chuenpagdee y Jentoft, 2009). De ahí nuestro interés de analizar en profundidad el cómo, cuándo y dónde surgen las AMPs (Chuenpagdee; Pascual-Fernández et al, 2013), y de examinar el potencial de estas figuras para mejorar la capacidad de gobernabilidad general de los sistemas socioecológicos y socioculturales envueltos. Este planteamiento teórico ha sido empleado sistemáticamente para el análisis de las AMPs en varios trabajos de nuestro grupo de investigación, y nos referimos a ellos para un desarrollo específico de determinados conceptos, dadas las constricciones de espacio en esta publicación (Chuenpagdee; Pascual-Fernández et al, 2013; Jentoft; van Son et al, 2007; Jentoft; Chuenpagdee et al, 2011; Jentoft; Pascual-Fernandez et al, 2012). 
Nos centramos sobre el caso de la Reserva Marina Punta de La Restinga-Mar de las Calmas, creada en 1996 en la población de La Restinga (El Hierro, Islas Canarias). Esta RM es considerada una de las de mayor éxito de todas las españolas en términos ecológicos, económicos y sociales. Ello es debido, principalmente, al papel desempeñado por los pescadores profesionales locales en su diseño, implementación y mantenimiento de la reserva; así como por el respaldo social e institucional del que disfruta. Esta RM se ha convertido incluso en un modelo "a seguir" frente a nuevas iniciativas de protección surgidas en el contexto español, como en el caso de la RM de Lira (Galicia) (González Ramallal y De la Cruz Modino, 2011).

La RM Punta de La Restinga-Mar de las Calmas es una de las mejor documentadas de todas las RRMM canarias, tanto a nivel ecológico como socioeconómico. Además de las series de datos históricos de pesca, y de las evaluaciones sobre el estado y efecto reserva en la zona, se ha llevado a cabo una extensa labor de campo en la población de La Restinga. Gracias al trabajo etnográfico se ha podido reconstruir el proceso de propuesta, diseño, declaración e implementación de la reserva; combinando el trabajo documental, empleando fuentes históricas e historiográficas, con entrevistas a informantes clave e informantes privilegiados. Entre el año 2001 y 2011 se han aplicado diversos cuestionarios entre la población residente y turista de La Restinga. También se han realizado multitud de entrevistas semiestructuradas a grupos de interés involucrados: investigadores, administradores, pescadores profesionales, empresarios locales, etc. Además, con el objetivo de recoger en detalle el proceso de protección desde el step zero, hemos seguido un modelo analítico diseñado a tal efecto dentro del proyecto GOBAMP que nos servirá para articular este texto. Para su aplicación ha resultado esencial conocer previamente las características socioculturales y socio-ecológicas del área objeto de protección y de sus poblaciones relacionadas, así como del contexto sociopolítico en el que se enmarcan aquellas. Luego, el análisis se ha desarrollado en torno a cuatro grandes unidades de trabajo:

a) Inspiración y promoción de la AMP; atendiendo a cuestiones tales como de dónde parte la propuesta de protección, quién la comunica, cómo se llevan a cabo los estudios iniciales que justifican la necesidad de proteger un ecosistema determinado, etc.

b) Diseño institucional de la AMP; atendiendo a cuestiones tales como qué organizaciones o instituciones se involucran en el proceso de diseño del AMP, cuáles son los objetivos y las metas de la propuesta de AMP, en qué medida surgen proyectos alternativos, qué agentes lideran estos procesos, etc.

c) Proceso de implementación y puesta en marcha de la AMP; atendiendo a cuestiones tales como las vías de participación local en el proceso, las fases o hitos destacados, la duración del proceso de implementación, etc. 
d) Conocimiento e imágenes de la AMP creada; evaluando la correspondencia entre la figura institucional creada y las dinámicas locales. Jentoft, Pascual et al., (2012) llevaron a cabo un estudio comparativo de tres casos españoles empleando el mismo análisis, del que nos hacemos eco en este texto.

\section{LA RESTINGA Y LA RESERVA MARINA PUNTA DE LA RESTINGA-MAR DE LAS CALMAS}

La población de La Restinga (Municipio de El Pinar) se localiza en la punta más meridional de la isla canaria de El Hierro. Aunque los vientos a menudo afectan a la Punta de La Restinga, el régimen habitual de los alisios (de dirección NE) asegura un acceso casi continuo a esta zona litoral y al "Mar de las Calmas", que debe su nombre al buen estado de la mar reinante durante la mayor parte del año. El pueblo fue fundado en la década de los cincuenta del siglo pasado, a raíz de una serie de expediciones pesqueras procedentes de la vecina isla de La Gomera, y hoy en día es el núcleo pesquero más importante de todo El Hierro. Alberga la única cofradía de pescadores de la Isla y a una población activa que roza el medio centenar de profesionales, entre armadores y marineros, que trabajan agrupados en 23 unidades productivas - UPAs. Se trata de la población de pescadores más joven de todas las Islas Canarias, siendo la edad media de los pescadores herreños de 41,6 años (Pascual Fernandez; Dorta Morales et al, 2011: 68). Tradicionalmente, las principales pesquerías se desarrollan en combinación con la llegada cíclica del bonito. Sin embargo, en estos últimos años las pesquerías que han aportado un mayor valor económico al conjunto de capturas, caracterizando las estrategias, métodos, barcos y artes de pesca de la zona, son las de la vieja (Sparisoma cretense), el peto (Acanthocybium solandri), las morenas de tierra (Muraena augusti, Gymnothorax unicolor), los alfunsiños (Beryx splendens y Beryx decadactylus) y las lapas (Patella candei y Patella ulyssiponensis). Éstas presentan altas frecuencias de captura a lo largo del año, y un buen nivel de reclutamiento en cuanto al número de UPAs que se dedican a ellas (Pascual Fernandez; Dorta Morales et al, 2011: 69). La pesquería del bonito se ha destinado tradicionalmente a la exportación, siendo comercializado por un único comprador hasta el fin de la década de los ochenta; mientras que la mayoría de las pescas de especies bentónicas (el denominado "pescado blanco") se destinaban al mercado local. En la actualidad una cooperativa local comercializa el grueso de las pescas de túnidos, aunque persiste el mismo agente comercializador de antaño, y la demanda de pescado blanco se ha visto probablemente alentada por el incremento de la actividad turística y la restauración.

A juicio de los pescadores la mejor "reserva" que existía en el entorno de La Restinga y el Mar de las Calmas, se constituía durante el periodo de la zafra del atún; cuando todos los profesionales se concentraban en la captura de túnidos (Katsuwonus pelamis y Thunnus albacares principalmente), dejando "descansar la orilla". La estrategia, todavía hoy en día 
es organizada por una cooperativa local creada en 1989. Esta gestionaba en la década de los noventa al conjunto de la flota y trabajaba como una sola unidad productiva durante los meses que duraba la zafra (Galván Tudela, 1990). Sin embargo, en estos últimos años la llegada de los flujos migratorios de los túnidos ha sido menor; y por otro lado, la cooperativa agrupa cada vez a un menor número de barcos (solo a un tercio de los pescadores aproximadamente en la actualidad) y no así al conjunto de los profesionales de antaño.

La población de La Restinga se mantiene en torno al medio millar de habitantes y su economía se articula sobre un sector servicios asentado en la oferta del turismo de buceo. Se trata del área receptora de mayor importancia del Sur de la isla y, de hecho, está contemplada como "polo turístico ambiental" en los planes de ordenación insulares, que pretenden convertir al binomio servicios-turismo en el pilar del desarrollo económico de toda la zona. Frente al crecimiento turístico experimentado en las últimas décadas hemos de destacar que, de manera formal e informal, la población local controla buena parte de las empresas de servicios-restauración y los servicios relacionados con el alojamiento, además del comercio al menor y los servicios de transporte. Sin embargo, la propiedad del suelo está muy repartida entre vecinos, herreños y foráneos. Todas las empresas que explotan directamente el buceo en el Mar de las Calmas pertenecen también a personas no originarias del pueblo.

La actividad del buceo autónomo con botella constituye el producto sobre el que pivota la mayor parte de la oferta turística de la zona sur de la isla de El Hierro; gracias al cual ha logrado cierta proyección internacional, alzándose como uno de los mejores destinos nacionales para la práctica del submarinismo. En el entorno de la reserva marina y del Mar de las Calmas se llevan a cabo otras actividades recreativas como el baño, el kayak, el snorkel, la navegación y la pesca recreativa; pero ninguna de éstas, aun comercializadas como productos turísticos, ha logrado una relevancia similar a la del buceo (De la Cruz Modino, 2004; De la Cruz Modino y Santana Talavera, 2008; De la Cruz Modino y Hernández Barbuzano, 2007).

Hoy en día los principales usuarios de la reserva y del Mar de las Calmas son los pescadores profesionales locales y los turistas buceadores. A éstos se añaden, en verano principalmente, pescadores de caña, que son en su mayoría turistas de proximidad o veraneantes procedentes de otras Islas Canarias. La cifra de empresas asentadas en el propio pueblo de La Restinga que comercializan el buceo es de nueve, y se mantiene estable desde hace años.

\subsection{INSPIRACIÓN, PROMOCIÓN Y CREACIÓN DE LA RESERVA MARINA}

La primera iniciativa de protección planteada sobre las aguas de la isla de El Hierro se remonta a la década de los ochenta. Se inspiraba en la reciente declaración de la RM de 
la Isla de Tabarca (Alicante, 1986) ${ }^{4}$, partió de la Universidad de La Laguna (Tenerife) y era de carácter conservacionista (Bacallado; Cruz et al, 1989). Sin embargo, no llegó a materializarse porque fue rechazada tajantemente por los pescadores de La Restinga. En palabras de uno de los investigadores de los que participaron en la primera propuesta: “(...) la primera vez que yo fui a La Restinga a explicar el porqué era bueno poner allí una reserva (...) tenía que dar una conferencia, fue hace muchísimos años, el 87 o quizás antes. Pues entonces me voy allá a dar una conferencia y los pescadores no querían entrar en la conferencia y había un jaleo (...). Aquello estaba lleno de gente (...) y había una serie de políticos, había senadores, había de todo. Entonces yo me puse a dar la charla, hablé con el alcalde de Frontera (...) entonces - los pescadores - vinieron con las escopetas cargadas y empezaron allí a darme leñazos cuando yo terminé la conferencia (...) y les dije: esto no se va a hacer a espaldas de ustedes, se tiene que hacer con ustedes, si no esto no se puede hacer $(\ldots)$ ".

En el año 1987, la propuesta de RM, tal y como fue planteada, no afectaba al "Mar de las Calmas" sino a la zona conocida como "las playas"; y según algunos pescadores en ella se cogía la mejor carnada para el atún, que representaba la pesquería más importante para la población por aquel entonces. Por otro lado, muy probablemente, la presencia en el pueblo de foráneos ajenos al sector pesquero, hombres de tierra que venían a hablar de imponer limitaciones a la actividad extractiva, simplemente no fue bien recibida por los pescadores en aquellos años (De la Cruz Modino, 2004: 140). A juicio de uno de los investigadores involucrado en la primera iniciativa $y$, con posterioridad, en la definitiva declaración de RM en el Mar de Las Calmas, las primeras reuniones resultaron infructuosas debido a que por aquel entonces no existía precedente alguno de creación de reservas marinas en las Islas Canarias. Las administraciones locales y estatales, pese a estar interesadas por la idea de protección, no apoyaron decididamente el proyecto; y tampoco existían apoyos o contactos hacia el interior de la población local.

$\mathrm{Al}$ margen de ese primer rechazo, durante la década de los noventa aparecieron en escena un estudiante de biología marina, hijo de un pescador local de La Restinga, quien mantenía contacto directo con aquel equipo de la Universidad, y un nuevo Vicepatrón en la Cofradía. En coordinación con la Universidad de La Laguna, los pescadores profesionales adoptaron toda una serie de acuerdos conducentes a la prohibición del uso de artes de pesca tales como los palangres y las nasas de pescado en la Isla; quedando así recogido en la legislación de la época (Orden de 27 de mayo de 1994, por la que

4. La RM de la Isla de Tabarca, la primera reserva española, se apoyó en la OM de 11 de mayo de 1982 (BOE n 125, 26 de mayo 1982) de repoblación marítima, perseguía proteger no tanto especies concretas como los fondos marinos y sus hábitats; y se ideó como una zona de múltiples usos, dividiéndose en tres áreas con distintos niveles de restricción respecto a las actividades científicas, recreativas y profesionales que podrían desarrollarse en su interior. 
se prohíbe el uso de las nasas para peces y se regula la pesca al puyón en las aguas interiores de la isla de El Hierro. Boletín Oficial de Canarias - BOC - no 072, de 13 junio de 1994). Además, de la mano del estudiante de biología y del nuevo Vicepatrón, se recuperó el proyecto de creación de una RM y fue nuevamente planteado pero en la cofradía. Según el estudiante citado, a diferencia de los ochenta, “(...) en los noventa los pescadores vieron la reserva con otros ojos, con cierto interés y con menos suspicacias". Los miembros del equipo de investigación de la Universidad habían mantenido el contacto con la población pesquera de La Restinga durante la realización de posteriores trabajos, y probablemente la presencia de este joven pudo ayudar a acortar distancias entre pescadores e investigadores. Se habían suprimido previamente, por iniciativa de los propios profesionales, artes y trampas que difícilmente habrían sido contempladas en la propuesta de RM. El proyecto en cierto modo sintonizaba, además, con las acciones iniciadas en pro de la sostenibilidad de las pesquerías locales.

Por otro lado, si bien los primeros años de la década que se iniciaba fueron prósperos para la pesca del atún, y se habían concretado estrategias económicas y pesqueras relevantes sobre esta pesquería, los años siguientes no registraron el mismo nivel de capturas. En años "malos" de atún, los pescadores ejercían un esfuerzo mayor sobre las pesquerías que comúnmente eran objetivos únicamente entre el otoño y el invierno. En algunas reuniones de la cofradía, los pescadores habían resaltado cómo ciertas capturas, tanto en la costa como "en el alto", estaban descendiendo; y se empezó a considerar la posibilidad de adoptar medidas de recuperación o repoblación, tales como la construcción de arrecifes artificiales.

A todo ello se unía el interés mostrado por las posibles restricciones que una figura de RM podía imponer sobre la pesca recreativa. En otras zonas del archipiélago, la pesca submarina por ejemplo, se estaba convirtiendo en una fuente de conflictos para la actividad profesional. Así se defendía en una reunión de la época: “(...) Lo que se recalca es el beneficio inmediato que el profesional tendrá ya que ningún barco que no sea de nuestro puerto podrá pescar en la reserva, además, el furtivo que cojan pescando de fusil en dicha zona o barco deportivo se le aplicará una ley muchísimo más severa que la que hay fuera de la reserva, ningún barco de recreo podrá ejercer un deporte de pesca en menos de doscientos metros de profundidad de la costa (...)"5.

El 29 de diciembre de 1994, la Cofradía de pescadores de Nuestra Señora de los Reyes, liderada por el Vicepatrón que mencionamos, elevó una petición por escrito al Director General de Pesca del Gobierno de Canarias con el fin de que se tomaran las medidas necesarias para evaluar la conveniencia de establecer una RM en la zona del Mar de Las Calmas. En sus propias palabras: "La Cofradía de Pescadores 'Nuestra Señora de

5. Fuente: Libros de Actas de la Cofradía Nuestra Señora de los Reyes, La Restinga (El Hierro). 
los Reyes' de la isla de El Hierro, se dirige a Vd. para exponer: Que en varias ocasiones hemos tratado la posibilidad de crear una reserva marina en nuestra isla, por el gran beneficio que esto pueda suponer a medio y largo plazo para nuestro sector. Lógicamente, después de tener el correspondiente asesoramiento técnico de la mano de uno de los grandes especialistas que tenemos en Canarias en temas marinos (...), y ver en teoría sus positivas consecuencias. Por todo esto, esperamos lo más pronto posible nos pongamos manos a la obra de una manera oficial y con una clara meta fijada. Por nuestra parte esperamos su respuesta, para sentarnos las partes interesadas y crear la reserva del Mar de Las Calmas en El Hierro". Las ventajas de crear una reserva en la zona, percibidas y defendidas por los pescadores de la cofradía, según se recoge en dicho escrito, se basaron: a) en la imposibilidad de que profesionales con base en otros puertos acudan a pescar tanto especies demersales como pelágicas a las zonas protegidas; b) en un incremento sustancial de la vigilancia, con inspectores dedicados exclusivamente a la zona; c) la exclusión de la pesca submarina y desde embarcación en el área; d) en la adopción de medidas reguladoras de otros usos turístico-deportivos como el submarinismo; e) en la generación de puestos de trabajo relacionados con el servicio de vigilancia y las labores de administración de la reserva ${ }^{6}$.

\subsection{LA IMPORTANCIA DEL LIDERAZGO Y LA NEGOCIACIÓN}

El que fuera el Vicepatrón de la cofradía durante los años noventa resultó ser el principal defensor de la RM Punta de La Restinga-Mar de las Calmas. Entre los años 1994 y 1996 defendió el proyecto con ímpetu asegurando que se trataba de una medida tendente a garantizar los recursos pesqueros y que los mayores beneficiarios a largo plazo serían los profesionales. Igualmente aseguró que no se crearía la RM si no se llegaba a un acuerdo. Otros intervinientes en el proyecto de RM que sí prosperó reconocen que: “(...) él ha sido quien ha manejado ahí a los pescadores (...)." Tal y como se lee en las actas de las reuniones de la Cofradía celebradas durante el año 1995, ante posibles quejas o reticencias el Vicepatrón actuó recalcando siempre que, en cualquier caso, los cofrades mantendrían la última palabra, la capacidad final de decisión: "S.A. pide la palabra para decir que él no está de acuerdo con eso - se refiere a los límites de la reserva- ya que no se podrá pescar desde la Punta de La Restinga hasta el final de Tifirabe y esa es la zona donde escapan unos cuantos barcos en invierno, el Vicepatrón le explica que eso no es así, que la única zona donde no se puede pescar es desde el Roque de Puerto Naos hasta el pesquero de La Herradura, en el resto no hay problema salvo que el $90 \%$ (de los pescadores) se pongan de acuerdo (...)" 7 .

6. Fuente: Escrito cedido por la Cofradía de Pescadores de Nuestra Señora de los Reyes, La Restinga (El Hierro).

7. Fuente: Libros de Actas de la Cofradía Nuestra Señora de los Reyes, La Restinga (El Hierro). 
A finales de 1995, los pescadores votaron en su cofradía la aprobación del proyecto de reserva en el Mar de Las Calmas. A diferencia de lo sucedido en los ochenta, esta vez, la iniciativa partía desde dentro de la población, basándose en problemas y soluciones identificadas por los propios pescadores locales. De 48 cofrades con derecho a voto, 40 votaron a favor. La RM Punta de La Restinga-Mar de Las Calmas se declaró el 24 de enero de 1996 (BOE no 39, de 3 de febrero de 1996) y por el decreto núm. 30/1996, de 16 de febrero, del Gobierno de Canarias (BOC no 31, de 11 de marzo de 1996) en el que además se consideraba bajo la categoría de Reserva Marina de Interés Pesquero. Puesto que el diseño de RM abarca tanto aguas interiores como exteriores, la Comunidad Autónoma de Canarias comparte su titularidad y la gestión con la administración estatal a través de sus administraciones pesqueras. Con respecto a la votación realizada en 1995, la definitiva orden de creación de la RM probablemente se demoró porque los profesionales de La Restinga intervinieron sobre el diseño de los órganos de gobierno, planteados originariamente por las administraciones titulares de la reserva. El primer borrador elaborado a tal fin no contemplaba la participación de los pescadores en la gestión de la RM, en la medida en que ellos estimaban imprescindible, por lo que su respuesta no se hizo esperar. Según se lee en una carta remitida por la Cofradía de pescadores Nuestra Señora de los Reyes a las administraciones autonómicas responsables, el 16 de julio de 1995: “(...) si la reserva del Mar de Las Calmas se crea a propuesta única y exclusivamente del propio sector pesquero de nuestra isla, nos parece increíble que en la propuesta de la formación del patronato de la reserva los representantes del sector no sean miembros de pleno derecho, sino en todo caso meros 'invitados' del patronato (...). Por todo lo anterior solicitamos: se ratifique el artículo 9 de dicha orden en el cual nos incluyan con dos miembros de pleno derecho en el patronato de la reserva del Mar de Las Calmas" ${ }^{8}$.

Durante el proceso de negociación existieron otras voces contrarias al proyecto. Siguiendo el modelo de Tabarca se dividió la zona proyectada en diferentes áreas con usos permitidos y prohibidos. La pesca profesional se podía (y se puede) ejercer en toda la reserva con diferentes limitaciones (aunque en el área integral solo sobre túnidos que entren en la zona), mientras que se prohibió el buceo en el área de reserva integral, se levantaron restricciones a la pesca recreativa ejercida con caña desde tierra (se prohibió en la misma zona integral), y se excluyó la pesca recreativa desde embarcación en toda el área bajo protección. Entonces buena parte de los empresarios de servicios turísticos locales solicitaron al Consejero de Turismo de la isla de El Hierro, su mediación ante la Secretaría General de Pesca Marítima (actualmente "Secretaría General del Mar" -SEGEMAR-). Tal y como expresaron públicamente, deseaban "la derogación de la imposibilidad de la práctica de actividades subacuáticas dentro de la zona integral de la

8. Fuente: Carta cedida en la Cofradía de Pescadores Nuestra Señora de los Reyes, La Restinga (El Hierro). 
RM (...) ya que consideran que perjudica gravemente los intereses turísticos de la zona", según se lee en una carta remitida el 8 de febrero de 1996. El propietario de una de las empresas de buceo asentadas en la localidad llegó a presentar incluso, ante la Audiencia Nacional, un recurso en el que recalcaba la disconformidad del sector empresarial. En 1998 la Audiencia Nacional dictó sentencia a favor del proyecto de RM en el Mar de las Calmas y en contra del empresario, haciendo hincapié en "(...) la falta de legitimación del recurrente para interponer este recurso, y por tanto, la inadmisibilidad del mismo..." Los empresarios de buceo, si bien fueron informados de la iniciativa de creación de la RM, nunca fueron envueltos en las negociaciones o en los procesos de discusión de su propuesta y diseño. No fueron considerados ni reconocidos como interesados o afectados. Se trataba de una cuestión de pesca, de una RM de "interés pesquero", y de un asunto de los pescadores del pueblo. La reserva se creó "por y para los pescadores"; con estas palabras lo justifican vecinos, administradores y pescadores, aún hoy en día en La Restinga.

\subsection{IMPLEMENTACIÓN Y SEGUIMIENTO DE LA RESERVA MARINA}

Las 750 hectáreas que comprende la RM Punta de La Restinga-Mar de Las Calmas se reparten entre aguas exteriores (mar territorial) y aguas interiores por lo que su titularidad se comparte entre el Estado y la Comunidad Autónoma de Canarias, siendo gestionada a través de la SEGEMAR y la Viceconsejería de Pesca del Gobierno de Canarias. En la siguiente tabla resumimos las características y los usos de la RM.

Punta de La Restinga- Mar de las Calmas Reserva Marina

\begin{tabular}{|c|c|c|c|c|}
\hline & TOTAL RM & $\begin{array}{l}\text { ÁREA DE RESERVA } \\
\text { INTEGRAL }\end{array}$ & ZONA DE AMORTIGUAMIENTO & RESTO DE RESERVA MARINA \\
\hline RESPONSABILIDAD & \multicolumn{4}{|c|}{ COMPARTIDA entre el estado y la CA de Canarias } \\
\hline AÑO DE DECLARACIÓN & \multirow{2}{*}{\multicolumn{4}{|c|}{$\begin{array}{r}1996 \\
1998\end{array}$}} \\
\hline IMPLEMENTACIÓN & & & & \\
\hline OBJETIVOS & \multicolumn{4}{|c|}{ Sosteniblidad de las pesquerías artesanales y consrvación } \\
\hline ÓRGANOS DE GOBIERNO & \multicolumn{4}{|c|}{ Comisión de Gestión y Seguimiento } \\
\hline SERVICIOS GENERALES & \multicolumn{4}{|c|}{ Servicio de vigilancia y centro de visitantes } \\
\hline $\begin{array}{l}\text { SEGUIMIENTO CINETíFICO Y } \\
\text { GESTIÓN DE ACTIVIDADES }\end{array}$ & \multicolumn{4}{|c|}{ Seguimiento de los puntos de buceo/monitoreo de las actividades subacuáticas/monitoreo de la actividad de pesca de caña desde tierra* } \\
\hline TAMAÑO (HAS) & 750 & 180 & 90 & 480 \\
\hline RANGO DE PROFUNDIDAD (m) & \multicolumn{4}{|c|}{$0-400$} \\
\hline HABITATS & \multicolumn{4}{|c|}{ Fondos rocosos, cuevas, mäerl, sustrato arenoso. La cubierta vegetal puede alcanzar los $70 \mathrm{~m}$ de profundidad } \\
\hline usos[5] & $\begin{array}{l}\text { Usos pesqueros } \\
\text { profesionales/usos } \\
\text { recreativos }\end{array}$ & $\begin{array}{l}\text { Pesca profesionale de } \\
\text { especies de túnidos }\end{array}$ & Pesca profesional/buceo** & $\begin{array}{l}\text { Pesca profesional/buceo/pesca recreativa desde } \\
\text { tierra***/otros usos recreativos }{ }^{* * * *}\end{array}$ \\
\hline PROHIBICIONES & \multicolumn{4}{|c|}{ Uso de fondeos/Pesca recreativa desde embarcación/Pesca submarina/El buceo con métodos artificiales de propulsión/otros usos extractivos diferentes a los } \\
\hline ARTES PERMITIDAS & Artes de pesca de anzuelo & Liña y caña para túnidos & \begin{tabular}{|l|} 
Artes de anzuelo (puyón y liña \\
principalmente), artes para la pesca del \\
atún, vara para petos
\end{tabular} & $\begin{array}{l}\text { Artes de anzuelo (puyón y liña principalmente), artes para la } \\
\text { pesca del atún, vara para petos, nasa para camarón (Plesionika } \\
\text { narval), tambores para morena (principalmente Muraena } \\
\text { augusti), gueldera o salemera (redes) para la captura de } \\
\text { carnada }\end{array}$ \\
\hline
\end{tabular}

*Estas actividades se realizan conjuntamente con las Universidades de Canarias, el Instituo Español de Oceanografía y empresas; *** La pesca recreativa sólo se realiza en la modalidad con caña desde tierra con la licencia de pesca de recreo correspondienteconcesionarias; ** Existen 11 puntos establecidos para el buceo dentro de la RM, el cual está sujeto a otras restricciones sobre el número de buceadores y la organización de la actividad; ${ }^{* * * *}$ Esas incluyen nadar, navegar y practicar buceo sin medios artificiales de respiración.

9. Fuente: Carta firmada en Madrid el 16 de diciembre de 1998 por el presidente de la Federación Nacional de Cofradías de Pescadores. Cedido por la Cofradía de Nuestra Señora de los Reyes, La Restinga (El Hierro). 
La pesca profesional está permitida, aunque con las limitaciones detalladas en la Tabla, en el interior de toda la RM. Cada cierto tiempo se elabora un censo de embarcaciones autorizadas a faenar en su interior, en base a un criterio de habitualidad. Ningún pescador, considerando que la mayoría son armadores en La Restinga, ha abandonado el censo aunque no se dediquen activamente a la actividad, salvo en caso de jubilación y/o desguace de la embarcación.

La ordenación de los medios para la gestión de la RM se atiende con las dotaciones que el Gobierno de Canarias y la SEGEMAR determinen para su eficaz cumplimiento. Esta reserva, ha contado además con la cofinanciación de los fondos del Instrumento Financiero de Orientación de la Pesca - IFOP- (BOC no 31 del lunes 11 de marzo de 1996; BOE núm. 30, de 3 de febrero de 1996). El Ministerio y el Gobierno de la Comunidad Autónoma de Canarias mantienen además convenios de asistencia y colaboración para la gestión compartida de las RRMM en Canarias. El Cabildo de El Hierro también participa en el mantenimiento de algunas infraestructuras de la RM y en acciones relacionadas con la divulgación y publicidad de la misma.

La puesta en funcionamiento de la RM ha requerido de la adecuación de diversas infraestructuras. En su entorno se han colocado mojones y carteles en tierra, y boyas de señalización en el mar. También se han construido un centro de visitantes y desde 1999 está en funcionamiento el servicio de vigilancia, que ha incorporado a tres antiguos pescadores y a un cuarto joven de origen local. De manera informal, prácticamente todos los pescadores del pueblo contribuyen a dichas labores. En el año 2001 se contrató a un técnico y a una administrativo/a que desarrollan las labores de coordinación de la vigilancia, seguimiento de las actividades que se desarrollan en la reserva y atención al público. La RM cuenta con una embarcación para desarrollar el servicio de vigilancia por mar.

Con el fin de gestionar la RM se ha creado una Comisión de Gestión y Seguimiento en la que se integran representantes de diversos colectivos e instituciones. Grosso modo, podríamos decir que en ella se hallan involucrados de alguna manera: la SEGEMAR, el Gobierno de Canarias, el Cabildo Insular de El Hierro y la Cofradía de Pescadores Nuestra Señora de los Reyes de La Restinga. Pero la composición de las comisiones puede sufrir alguna modificación en sus reuniones, pudiendo asistir otros usuarios e interesados, como por ejemplo representantes de administraciones e instituciones científicas españolas. Las comisiones no representan un órgano autónomo de gestión de nivel local (Batista Medina y Pascual Fernández, 2005), sino que se parecen más a un foro en el que se informa de ciertos asuntos, se comentan problemas y se plantean posibles líneas de actuación. A pesar de que sus decisiones son vinculantes, este órgano no tiene poder de ejecución autónomo, haciendo las veces de filtro o de interlocutor final entre la dimensión estrictamente local y estatal/regional de la reserva. De semejante manera, los 
coordinadores no tienen capacidad de decisión autónoma y su labor es principalmente organizativa sobre cuestiones de coordinación, información y vigilancia. La comisión se reúne generalmente una vez al año para examinar los resultados del ejercicio anterior, y determinar las inversiones y gastos previos para el próximo (BOE núm. 12, de 15 de junio de 1999). En ella se exponen las necesidades y los logros de la reserva que, en líneas generales engloban los gastos de mantenimiento y control sobre señalizaciones marítimas y terrestres, y puesta en marcha de campañas de divulgación e información. La Comisión de Gestión y Seguimiento trata las acciones que pudieran ser adoptadas tanto con coste económico como sin coste, aunque no disponga de un fondo propio para afrontarlas. Los empresarios de buceo y otros interesados solo han sido invitados a asistir a dichas reuniones en alguna ocasión, disfrutando de voz pero no de voto.

En el año 2005 se levantaron toda una serie de limitaciones a la actividad del buceo en la RM, con anterioridad tan solo pesaban restricciones de tipo espacial sobre ella. Entre las más importantes debemos mencionar que se limitó el número de buceadores que podían realizar inmersión en los puntos habilitados para ello en el mar, y se impusieron una serie de requisitos a las empresas que explotaban la actividad en La Restinga. La medida, aunque común en el conjunto de RRMM de responsabilidad estatal, fue "reclamada" y apoyada por los pescadores. Durante años este sector ha mirado con recelo a los empresarios, considerados como "extraños", como "extranjeros o forasteros" que obtienen beneficios económicos de una actividad que desarrollan en exclusiva. Existen relaciones de vecindad entre los dos grupos y el reconocimiento (mutuo) de que ambos son importantes para el desarrollo del pueblo. Pero los pescadores profesionales son reticentes ante el hecho de que sus "esfuerzos" - autolimitándose en el Mar de las Calmas_ sean "aprovechados por otros".

La Cofradía de Pescadores Nuestra Señora de los Reyes de La Restinga ha intervenido en cuantos procesos de toma de decisión se desarrollan afectando al sector de la pesca y del turismo en el Mar de Las Calmas, contando generalmente con el apoyo, o al menos con la "no" oposición, de las administraciones locales, insulares y regionales. Estas últimas suelen actuar concediendo a los pescadores un papel principal, protagonista, frente a los cambios que pudieran afectar al sector pesquero profesional artesanal o de bajura. Papel que, por otro lado, los pescadores han sabido mantener y/o demandar, a través de su Cofradía y representantes. Participar, en este caso, y refiriéndonos concretamente al planteamiento, creación, implementación y gestión de la RM, no se ha reducido a la mera información o consulta sino que se ha materializado en una capacidad de decisión autónoma, aun matizada dentro de la estructura formal de gestión de la reserva.

\section{LAS CLAVES EN EL STEP ZERO}

Los análisis de las medidas de protección, tales como las AMPs, no deberían enfocarse únicamente sobre su implementación. Los pasos anteriores a su concepción e inicio, 
conocer cómo es el proceso de establecimiento de las AMPs, pueden ayudarnos a entender y examinar cuán gobernables resultarán las medidas.

Quién, cómo y dónde se plantea la propuesta de RM Punta de La Restinga-Mar de las Calmas

Una de las primeras cuestiones que llama la atención del proyecto de 1996, al respecto del de 1987, es que la "idea” de establecer una RM en el Mar de las Calmas resurge en la propia Cofradía de pescadores; fruto del diálogo entre los representantes de la cofradía y los investigadores. Frente a las reacciones negativas ante una idea de conservación que es "presentada" a los pescadores en 1987, en 1996 son los representantes de los pescadores los que promueven la conservación del Mar de las Calmas, y son ellos los que presentan la idea a las autoridades y la comunican al resto de los pescadores.

De qué manera se discute o negocia la RM Punta de La Restinga-Mar de las Calmas

Aunque los investigadores de la Universidad de La Laguna realizaron en los años ochenta los estudios conducentes a la protección del mar herreño (Bacallado; Cruz et al, 1989), los pescadores negociaron en los noventa los límites de la futura RM dentro de la propia Cofradía, en un proceso que duró al menos dos años. Entendemos que, durante este tiempo, el apoyo de los científicos y de las administraciones, dejando siempre el espacio suficiente para que fueran los pescadores quienes ejercieran la última palabra, resultó crucial, al igual que la adopción previa de otras medidas de protección de los recursos pesqueros, suprimiendo las nasas y los palangres. También es relevante en este sentido la experiencia de creación de la cooperativa, pues se trató de un proceso asambleario donde los pescadores se vieron abocados a discutir, establecer pautas de organización, y cambiar o renovar las formas de participación por su trabajo y los medios de producción (barcos, artes, infraestructuras demandadas en tierra, etc.) que pusieron al servicio de la empresa en común (De la Cruz Modino, 2012: 56).

Cuál es la idea o imagen de RM que se forja

Una imagen es una representación sobre cómo es algo y/o cómo debería ser; pueden ser descriptivas, pero también normativas (Jentoft; Chuenpagdee et al, 2010; Jentoft; PascualFernandez et al, 2012). Tiene poco que ver la RM que fue "presentada" a los pescadores en los años ochenta por parte de los investigadores; en una reunión formal, compartiendo aforo con otras autoridades locales; que la RM que los propios pescadores ayudaron a dibujar dentro de su Cofradía, discutiendo (prácticamente) punto por punto el proyecto durante casi dos años. El fin de la protección es compartido por ambos proyectos, pero las imágenes de cada RM difieren enormemente, de resultar algo de "otros" a convertirse en algo "propio". La RM creada e implementada en La Restinga finalmente es una "reserva marina de interés pesquero".

Es importante resaltar que la RM siempre se plantea como una medida para proteger 
los recursos pesqueros y favorecer la continuidad de la pesca artesanal en el Mar de las Calmas. Así se sectoriza la RM como un área de múltiple uso, respetando las características y necesidades de las pesquerías tradicionalmente ejercidas en la zona.

Existe una fuerte identidad asociada con los orígenes pesqueros de La Restinga y con el Mar de las Calmas, concebido como un espacio de trabajo para los pescadores locales (Galván Tudela, 1990, 1997). Como hemos visto, cuando el mismo entorno comienza a ser "explotado" por "otros", los pescadores respondieron con recelo y se limitó la intervención de sectores ajenos a la pesca, sirviéndose de la propia RM enarbolada como una figura de "interés pesquero" (Pascual-Fernandez y De la Cruz Modino, 2011). Con ello se ha reforzado la apropiación simbólica de los pescadores locales sobre el Mar de las Calmas.

Cuál es el rol de los restantes implicados

El papel ejercido por las administraciones locales, regionales y nacionales es de apoyo cuando los pescadores lo exigen, salvando algunos conflictos recientes con el Cabildo de la Isla. Los sectores asociados al turismo, a pesar del crecimiento experimentado en las últimas décadas en esta zona del sur de la isla, se han visto, en cierto modo, sometidos ante la normativa y la gestión de la RM. Los empresarios de buceo representan un colectivo de interesados "expectantes" (Buanes; Jentoft et al, 2004), que esperan que sus demandas y preocupaciones se tengan en cuenta. Ciertamente son usuarios directos y afectados por las medidas adoptadas, pero no tienen el poder de influir en los procesos o mecanismos de toma de decisión en torno a la RM (De la Cruz Modino, 2012: 35).

Cuál es el estado socioecológico previo y en qué medida satisface el AMP las necesidades detectadas

Cuando en los noventa se retomó la idea de crear una RM en El Hierro, las pescas de túnidos están en alza y aspectos importantes de su comercialización habían mejorado gracias a la creación de la cooperativa (De la Cruz Modino, 2012: 53 y ss.). No obstante, en estos años, se apreciaron signos de desgaste sobre otras pesquerías igualmente relevantes debido al carácter temporal de la zafra del atún. La RM tiene un diseño lo suficientemente ajustado como para favorecer la recuperación de especies y hábitats clave en este sentido, a la vez que permite el desarrollo de la zafra en su interior. Por otro lado, aunque se prohibió la captura de carnada en el interior de la RM, también se limitó el acceso a los barcos que fueran ajenos a la Cofradía local. La reserva, de alguna manera, ayudó a controlar el recurso en la medida en que limitaba los usuarios, favoreciendo claramente las estrategias de producción de los pescadores artesanales locales. Asumimos que el hecho de que fuera una administración pesquera la responsable de la implementación de la RM ha podido resultar esencial para que el AMP diera respuesta a problemas pesqueros, y no estrictamente medioambientales, detectados en la localidad. 
Merece la pena destacar que frente a la inestabilidad de las zafras durante la primera década del dos mil, la RM ha podido contribuir al mantenimiento de las pesquerías de especies de "pescado blanco", como las viejas; cuya demanda para la restauración se ha incrementado notablemente con el afianzamiento de La Restinga como destino turístico. Existe cierta conciencia entre los pescadores de que sin la RM, en ausencia de túnidos, no se habría mantenido la actividad pesquera con los niveles denotados (Garcia-Charton; Perez-Ruzafa et al, 2008; Tuya; Ortega-Borges et al, 2006).

\section{CONCLUSIONES}

Las áreas marinas protegidas son un producto humano en cualquiera de sus versiones y el resultado de un proceso de negociación, con independencia de si se apoyan más o menos en el marco de la ley, de la ciencia, en prohibiciones explícitas procedentes de alguna autoridad moral o de si están basadas en acuerdos informales entre sus usuarios. Un AMP tiene su historia, su origen, dando comienzo en el mismo momento en el que sus implicados las imaginan de una manera determinada y se sientan a negociar. Frente a las posibilidades y limitaciones de las meras medidas de cierre a usos pesqueros o recreativos, en torno a las AMPs se institucionalizan nuevas fórmulas de toma de decisiones, afectando al poder de diferentes colectivos de usuarios e interesados del litoral. Es en este sentido en el que las medidas de protección de la naturaleza contribuyen a la gobernabilidad local, y no únicamente favoreciendo la recuperación ecológica o el desarrollo socioeconómico.

En el caso de La Restinga, la RM entendida y defendida como una medida de interés pesquero, con el amparo de la ley, ha ayudado a reforzar la identidad local y a proteger los intereses del colectivo de pescadores artesanales frente al avance del sector serviciosturismo o de las actividades recreativas sobre su tradicional área de trabajo. Creemos que parte del éxito de esta RM, es ese rol de los pescadores liderando y creando nuevas oportunidades frente a los cambios que se suceden en su entorno ecológico y social. El análisis del proceso de creación de la RM Punta de La Restinga-Mar de las Calmas nos ha permitido ver a pescadores respondiendo a problemas pesqueros, con herramientas que lograban construir conjuntamente con administradores y científicos; de ahí su éxito a largo plazo.

Muchas de las áreas protegidas, en el mar o en tierra, son contempladas por las poblaciones locales vinculadas a esos espacios como algo ajeno, impuesto por extraños que no conocen, con unas reglas que no acaban de entender. De ahí gran parte de los conflictos que, con demasiada frecuencia, acaecen en torno a ellas. Uno de los factores clave en este terreno son las imágenes, las representaciones mentales que la gente construye en torno a instituciones como las AMPs, como lo hace también sobre muchos otros aspectos de la realidad. Los modelos de áreas protegidas suelen ser extrapolados de otros contextos y superpuestos a escenarios locales completamente diferentes, sin 
que los usuarios puedan participar en el proceso de construcción de esas instituciones que se están levantando sobre espacios que, en mayor o menor medida, quizás habían considerado como propios durante largo tiempo. Uno de los elementos interesantes de este caso es cómo los pescadores retomaron una propuesta diseñada por biólogos y, con la ayuda de estos y de las administraciones, terminaron construyendo un diseño institucional que se ha demostrado relativamente exitoso. Lo importante aquí no es el diseño institucional final, casi igual al de otras reservas marinas de interés pesquero que han sido una fuente continua de conflictos. Lo importante realmente es el proceso de incepción, que condujo a que los locales construyeran una imagen de la RM como algo propio, positivo, construido por ellos, que les ayuda a conservar los recursos de los que dependen y que desean defender. Si los locales tienen una imagen de este tipo sobre una institución, lo lógico es que colaboren en su éxito.

Los sistemas naturales y sociales que deben ser gobernados, comprenden una serie de cualidades estructurales que los sistemas de gobierno deben tomar en cuenta, ya que los primeros establecen las condiciones bajo las cuales los sistemas de gobierno operarán (Kooiman; Bavinck et al, 2005). Tal y como hemos visto en el caso de La Restinga, este ajuste debe comenzar desde el primer momento en que se plantea una medida como las de RM. Una mejor o "buena gobernanza" pasa por considerar las características sociohistóricas, organizacionales, socioeconómicas, pero también coyunturales de los grupos de población local donde se implementan las medidas de protección. Los sistemas de gobierno deben ser sensibles, inclusivos, flexibles y atender a la precaución (Chuenpagdee y Jentoft, 2009). Por ello, la gobernabilidad de las AMPs comienza con su nacimiento, o mejor dicho, antes de su nacimiento. Es necesario enfatizar los esfuerzos que hay que colocar sobre las etapas tempranas de los espacios protegidos, tanto en mar como en tierra. Las AMPs dependen en gran medida de los consensos que lleguen a ser generados, tanto entre los grupos de población local, otros colectivos de usuarios e interesados, como para con los diversos entes de la administración. Las AMPs, recién nacidas, necesitan de atención y consenso, no conflictos a su alrededor. Aunar imágenes, voluntades, intenciones e incluso intereses -especialmente en las primeras etapas de diseño e implementación de las mismas- puede rendir dividendos sustanciales, en términos de gobernabilidad, para el futuro. 


\section{REFERENCIAS BIBLIOGRÁFICAS}

Bacallado, Juan José; Cruz, Tomás; Brito, Alberto; Barquín, Jacinto y Carrillo, Manuel (1989) Reservas marinas de Canarias. Canarias: Consejería de Agricultura y Pesca de Canarias Secretaría General Técnica.

Batista Medina, José Antonio y Pascual Fernández, José J. (2005) “Espacios marinos protegidos, pescadores y Estado: la participación local en la Reserva Marina de La Palma (Islas Canarias)". En Pascual Fernández, José y Florido del Corral, David (Eds.), ¿Protegiendo los recursos? Áreas protegidas, poblaciones locales y sostenibilidad. Sevilla: Fundación El Monte, FAAEE, Asociación Andaluza de Antropología, pp. 63-82.

Buanes, Arild; Jentoft, Svein; Karlsen, Geir Runar; Maurstad, Anita y Soreng, Siri (2004) "In whose interest? An exploratory analysis of stakeholders in Norwegian coastal zone planning". Ocean \& Coastal Management, 47(5-6), pp. 207-223.

Chuenpagdee, Ratana y Jentoft, Svein (2007) "Step zero for fisheries co-management: What precedes implementation”. Marine Policy, 31(6), pp. 657-668.

Chuenpagdee, Ratana y Jentoft, Svein (2009) "Governability Assessment for Fisheries and Coastal Systems: A Reality Check”. Human Ecology, 37(1), pp. 109-120.

Chuenpagdee, Ratana; Pascual-Fernández, Jose J.; Szeliánszky, Emese; Luis Alegret, Juan; Fraga, Julia y Jentoft, Svein (2013) "Marine protected areas: Re-thinking their inception". Marine Policy, 39(0), pp. 234-240.

De la Cruz Modino, Raquel (2004) Gestión de los recursos: turismo, usos y apropiación del patrimonio natural. Tesis de Licenciatura. La Laguna: Universidad de La Laguna, Facultad de Filosofía, sin publicar (217 pp.).

De la Cruz Modino, Raquel (2012) Turismo, pesca y gestión de recursos. Aportaciones desde La Restinga y L'Estartit. Madrid: Ministerio de Educación, Cultura y Deporte.

De la Cruz Modino, Raquel y Hernández Barbuzano, Idaira (2007) Comercialización y distribución de productos turísticos marinos en El Hierro a través de Internet. La Laguna, Tenerife: Trabajo Fin de Máster. Universidad de La Laguna, Facultad de Ciencias Económicas y Empresariales. Máster en Gestión de Empresas Turísticas (MGET) [Sin publicar]. (59 pp. + Anexos).

De la Cruz Modino, Raquel y Pascual Fernández, José J. (2011) “Acción colectiva y políticas públicas de gestión marítimo-costera: el ejemplo de las reservas marinas en las Islas Canarias". Revista Atlántida, 3, pp. 65-86.

De la Cruz Modino, Raquel y Santana Talavera, Agustín (2008) "El turismo de buceo en La Restinga (Islas Canarias) y L'Estartit (Cataluña): AMPs, clasificaciones e impactos". En Beltrán Costa, Oriol; Pascual Fernández, José y Vaccaro, Ismael (Eds.), 
Patrimonialización de la naturaleza: el marco social de las políticas ambientales. Donostia: Ankulegi Antropologia Elkartea, pp. 223- 244.

Galván Tudela, Alberto (1990) “'Pescar en grupo': De los azares ambientales a los factores institucionales (La Restinga, El Hierro)”. Eres (Serie de Antropología): 2, pp. 39-60.

Galván Tudela, Alberto (1997) La identidad herreña. La Laguna: Centro de la Cultura Popular Canaria-Cabildo del Hierro.

Garcia-Charton, J. A.; Perez-Ruzafa, A.; Marcos, C.; Claudet, J.; Badalamenti, F.; Benedetti-Cecchi, L.; Falcon, J. M.; Milazzo, M.; Schembri, P. J.; Stobart, B.; Vandeperre, F.; Brito, A.; Chemello, R.; Dimech, M.; Domenici, P.; Guala, I.; Le Direach, L.; Maggi, E. y Planes, S. (2008) "Effectiveness of European Atlanto-Mediterranean MPAs: Do they accomplish the expected effects on populations, communities and ecosystems?". Journal for Nature Conservation, 16(4), pp. 193-221.

González Ramallal, Manuel E y De la Cruz Modino, Raquel (2011) A model of MPAs? The cases of Lira and La Restinga marine reserves of fishing interest (MRFI). Amsterdam: Paper presented at Mare Conference: People and the Sea VI: Bridging Science and Policy for Sustainable Coasts and Sea, July 6-11, 2011, sin publicar.

Hoyt, Erich (2005) Marine protected areas for whales, dolphins, and porpoises: a world handbook for cetacean habitat conservation. London: Earthscan.

Jentoft, Svein; Chuenpagdee, Ratana; Bundy, Alida y Mahon, Robin (2010) "Pyramids and Roses: Alternative Images for the Governance of Fisheries Systems". Marine Policy, 34(6), pp. 1315-1321.

Jentoft, Svein; Chuenpagdee, Ratana y Pascual-Fernandez, Jose J. (2011) "What are MPAs for: On goal formation and displacement”. Ocean \& Coastal Management, 54, pp. 75-83. Jentoft, Svein; Pascual-Fernandez, Jose; De la Cruz Modino, Raquel; Gonzalez-Ramallal, Manuel y Chuenpagdee, Ratana (2012) "What Stakeholders Think About Marine Protected Areas: Case Studies from Spain”. Human Ecology, 40(2), pp. 185-197.

Jentoft, S.; van Son, T. C. y Bjorkan, M. (2007) "Marine protected areas: A governance system analysis". Human Ecology, 35(5), pp. 611-622.

Kelleher, Graeme y Kenchington, R. A. (1992) Guidelines for establishing marine protected areas. Gland, Switzerland: IUCN in collaboration with Great Barrier Reef Marine Park Authority.

Kooiman, Jan (2008) "Exploring the Concept of Governability". Journal of Comparative Policy Analysis, 10(2), pp. 171-190.

Kooiman, Jan; Bavinck, Maarten; Jentoft, Svein y Pullin, Roger (Eds.) (2005) Fish for Life: Interactive Governance for Fisheries. Amsterdam: Amsterdam University Press. 
Pascual-Fernandez, Jose J. y De la Cruz Modino, Raquel (2011) "Conflicting gears, contested territories: MPAs as a solution?". En Chuenpagdee, Ratana (Ed.), World smallscale fisheries contemporary visions. Delft: Eburon, pp. 205-220.

Pascual Fernandez, José J.; Dorta Morales, Carmelo; De la Cruz Modino, Raquel y Rodríguez Darias, Alberto Jonay (2011) Información y diagnostico general relativo a la Zona de Pesca 1, El Hierro. Estudio encargado por la Viceconsejería de Pesca. La Laguna: Instituto Universitario de CC. Políticas y Sociales (sin publicar).

Prats i Català, Joan (2005) De la burocracia al management, del management a la gobernanza: las transformaciones de las Administraciones Públicas de nuestro tiempo. Madrid: Ministerio de Administraciones Públicas.

Revenga, Silvia (2003) "Las Reservas Marinas Canarias (España)". En Moreno, Diego y Frías, Antonio (Eds.), Actas de las I Jornadas sobre Reservas Marinas y I Reunión de la Red Iberoamericana de Reservas Marinas (RIRM). Cabo de Gata, Almería 17-23 de Septiembre de 2001. Madrid: Publicaciones del MAPA, Secretaría Técnica, Madrid, pp. 101-111.

Salm, Rodney V.; Clark, John R. y Siirila, Erkki (2000) Marine and coastal protected areas: a guide for planners and managers. Gland, Switzerland; Washington DC: IUCN.

Suárez de Vivero, J. L. y Rodríguez Mateos, Juan Carlos (2007) Atlas de la Europa marítima: jurisdicciones, usos y gestión. Barcelona: Ediciones del Serbal.

Tuya, F.; Ortega-Borges, L.; Sanchez-Jerez, P. y Haroun, R. J. (2006) "Effect of fishing pressure on the spatio-temporal variability of the parrotfish, Sparisoma cretense (Pisces: Scaridae), across the Canarian Archipelago (eastern Atlantic)". Fisheries Research, 77(1), pp. 24-33. 